$\mathrm{Oz}$

Volume 24

Article 8

$1-1-2002$

\title{
The Sedimentation of an Architect
}

Matthius Altwicker

Follow this and additional works at: https://newprairiepress.org/oz

(c) $($ ) $\Theta \Theta$

This work is licensed under a Creative Commons Attribution-Noncommercial-No Derivative Works 4.0 License.

\section{Recommended Citation}

Altwicker, Matthius (2002) "The Sedimentation of an Architect," Oz: Vol. 24. https://doi.org/10.4148/

2378-5853.1374

This Article is brought to you for free and open access by New Prairie Press. It has been accepted for inclusion in Oz by an authorized administrator of New Prairie Press. For more information, please contact cads@k-state.edu. 


\title{
The Sedimentation of an Architect
}

\author{
Matthius Altwicker
}

A scale in terms of 'time' rather than 'space' took place. The mirror itself is not subject to duration, because it is an ongoing abstraction that is always available and timeless. The reflections, on the other hand, are fleeting instances that evade measure. Space is the remains, the corpse, of time, it has dimensions. 'Objects' are 'sham space', the excrement of thought and language. Once you start seeing objects in a positive or negative way you are on the road to derangement.'

-Robert Smithson

Every project raises the question of form: it pushes us to our outer aesthetic limits, nearer to the essential and fundamental question of anti-form. One might even call this idea a mutation of architecture-design in the direction of architecture-landscape...Such an approach would introduce a landscape innocent of exclusions, made of everything, for everyone. That would be an entirely positive thing. ${ }^{2}$

-Dominique Perrault

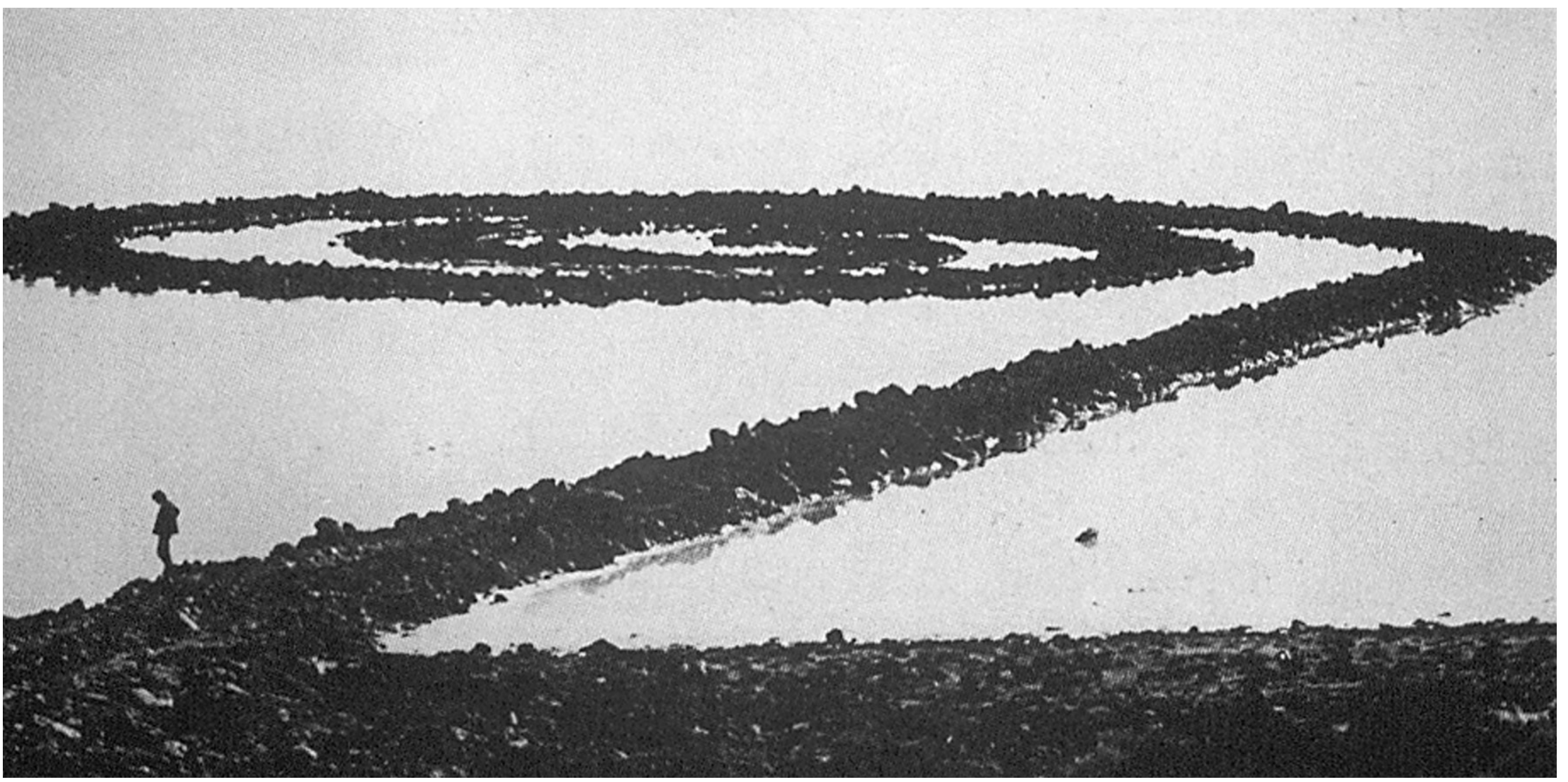




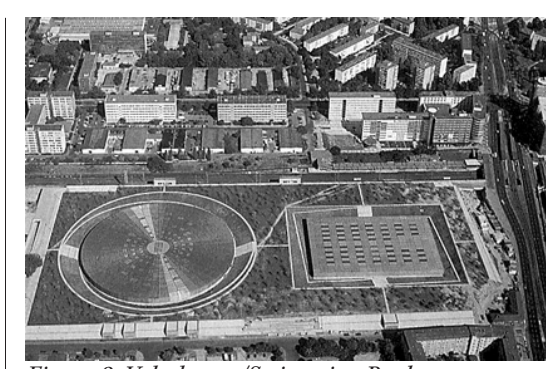

Figure 2. Velodrome/Swimming Pool.

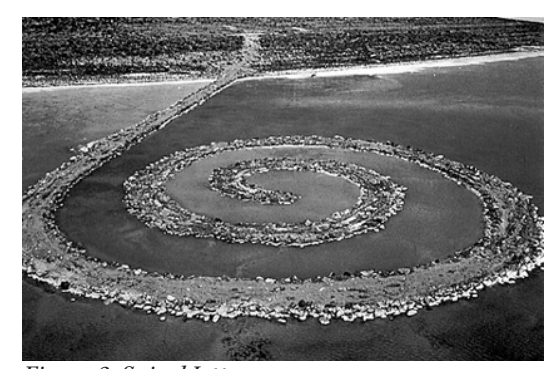

Figure 3. Spiral Jetty.

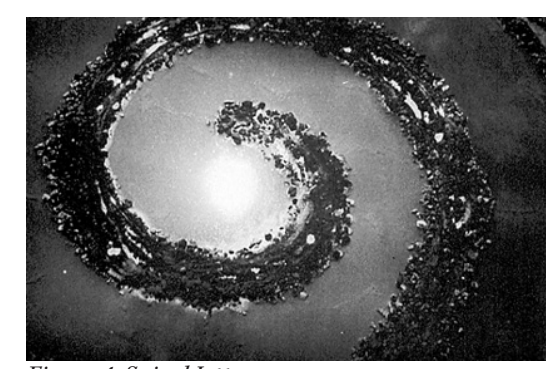

Figure 4. Spiral Jetty.

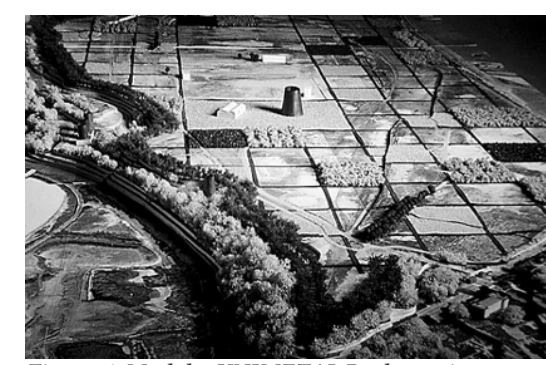

Figure 5. Model-UNIMETAL Reclamation. physical context, but engage, on a daily basis, the greatest number of people. Perrault's architecture expands upon the artists' themes of timeless-ness and scaleless-ness while sharing their methodologies of investigation and material use, drawing relationships not only between the natural and the man-made but between the realms of architecture, landscape, and art.

Smithson's theory of site/non-site becomes the starting point for understanding the development of Perrault's architecture, in particular the Velodrome/Swimming Pool Complex in Berlin (1992-99). [Fig. 2] The theory proposes the de-differentiation of site and intervention; a hierarchical oscillation between the project, its representation, and the site conditions through time. ${ }^{4}$ Each element of a project's development or documentation is thus understood as part of the site, neutralizing any formal, scalar, or historical hierarchies. This eliminates methods of site engagement, so that techniques of investigation must be rethought as being part of the site/ project as opposed to being merely representative thereof.

In the Spiral Jetty (1972), Smithson used the developed image (film, photograph) as a means of removing the site from its immediate physical condition to allow an analytic understanding of the subject. [Fig. 3] These images, each with a specific point of view, also edit the given context through scale and distance, so that larger relationships between elements become clearer to the artist and the viewer. The subsequent revision occurs both through the technique of interaction, which could be termed a mapping procedure, and the scale of the intervention itself. ${ }^{5} \mathrm{Film}$ is then used to reorder the various scales of the project. The specific, looped maneuvering of the airplane during the making of the documentary film reinforces the relationships between the sun, the piece, and the plane's flight path around the project while filming. ${ }^{6}$ [Fig. 4] Flight around the piece completes our understanding; by contrast, walking to the end of the jetty seems almost anticlimactic; the piece remains static and flattened. [Fig. 1]

The aerial vantage point opens up the possibility for another level of understanding, beyond that of earthbound experience, ${ }^{7}$ For Perrault's urbanization studies, this engagement can take the form of building a model into an aerial photograph or drawing into a photograph or plan of the context. ${ }^{8}$ The model of the intervention, built onto the image, grows directly out of the abstracted context. [Fig. 5] The drawings fuse the historical layers of the site with the newer, conceptual layers by depicting both the new (white pencil and photomontage) and the old (original photo) site conditions while allowing them to maintain their own individual identity. [Fig. 6] The idea of montage, or covering up one layer with another, is rejected for a transparency that allows a simultaneous understanding of all of the elements. In the case of Smithson's quarry projects, drawing into the context became a way to deal 


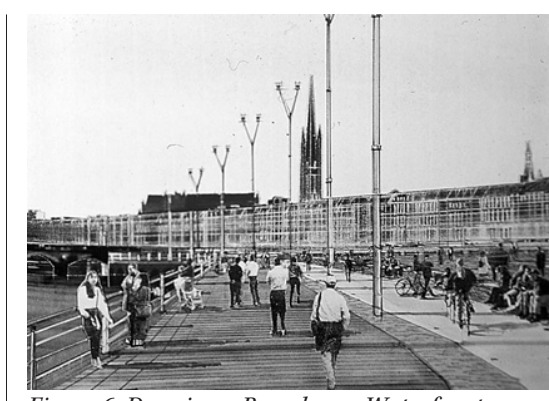

Figure 6. Drawing-Bourdeaux Waterfront.

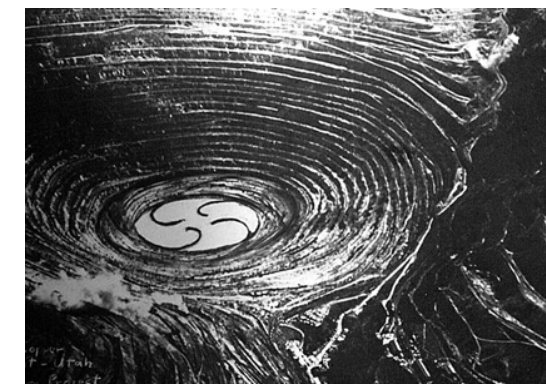

Figure 7. Drawing-Bingham Copper Mine.

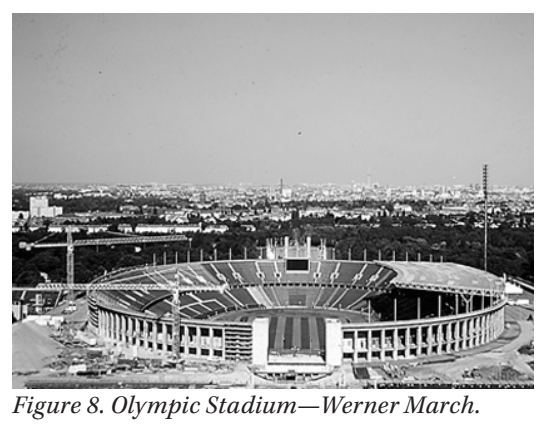

configurations and the objectification of the arena with the city elements as a backdrop, opting instead for timeless-ness by being embedded in and simultaneous with multiple moments in time. The Velodrome's rejection of associations with the representative or the monumental further intensifies a dialectical relationship with the city's most recognizable arena, the Olympic Stadium by Third Reich architect Werner March (1934-36). [Fig. 8] Its formalization through axial siting and monumental stone cladding site the project monumentally in a specific time, in direct contrast to the Velodrome's conception of being sited in relationship to time. For Perrault, an appropriate architectural response generated out of lived experience will automatically refer to time in general rather than one specific time, so that

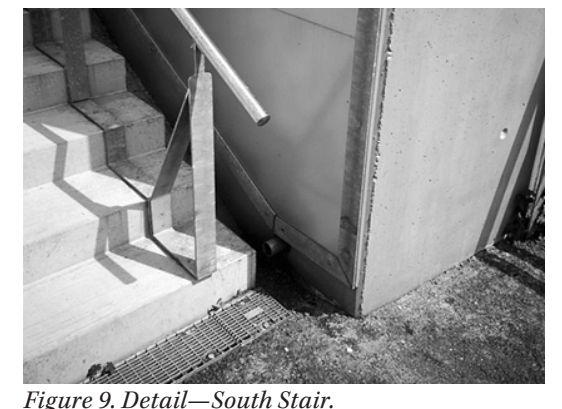

Figure 9. Detail-South Stair. the project can never become reducible to one specific image or narrative. ${ }^{13}$

It is Perrault's precise use of materials that embeds the architecture to the site and to time: "It is always more rewarding to concern oneself with matter; that is, with a field which has to do with sensuality. The grey of concrete, the finish of metal, the wooden elements that create a mass, all these things make for a kind of plentitude." ${ }^{14}$ All traces of the Velodrome's construction, without exaggeration, are clearly legible for the visitor. Connections between materials are typical and left exposed. Concrete is cast in a standard grey except for the stair surfaces approaching the park these are pigmented white and cast in wooden forms. From a distance, the stairs read as a continuous white relief while, upon climbing the stairs, the

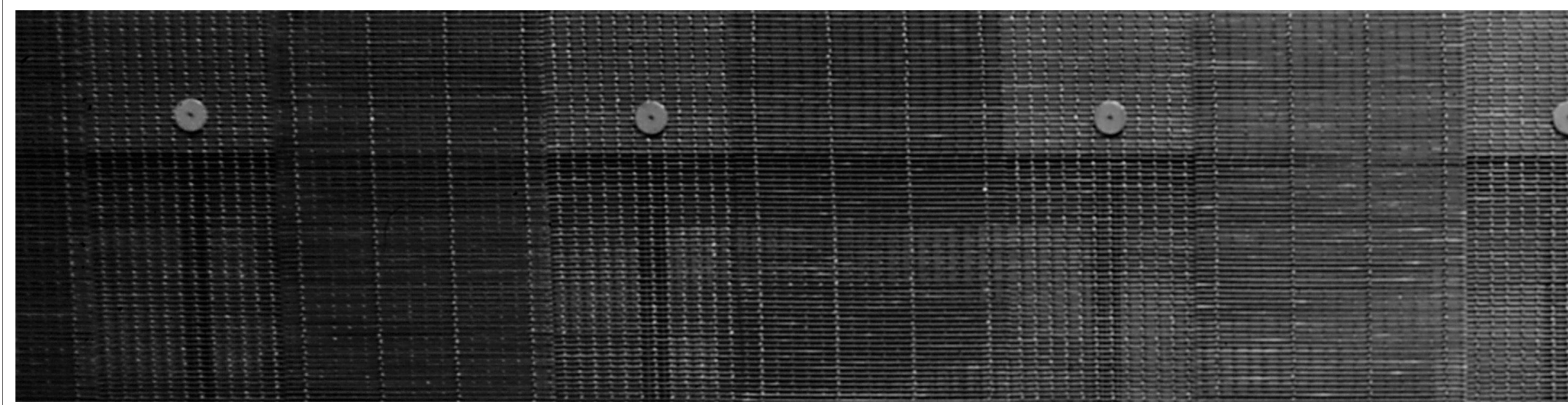



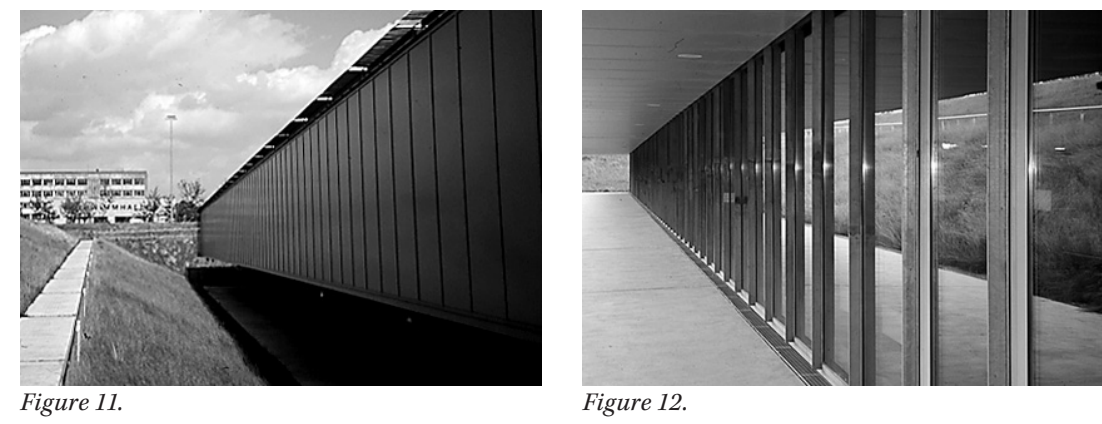

Figure 12.

texture reveals itself to closer visual inspection. [Fig. 10] Metal work is left in its raw state but is activated by its interaction with sunlight, ranging from a dull grey to a brilliant gold, depending on the sun's angle and intensity. [Fig. 10] This ever-changing effect occurs in the park surface; the winds across the park subject the tall grasses, interspersed with flowerbeds, to a constant shifting that results in a shimmering effect equivalent to sunlight on the metal skin. [Fig. 11] Glass and metal are used for their reflectivity-from a distance, the glass mirrors the context, be it the park or the rail line, masking the building's perimeter and scale. These varying degrees of reflectivity, resulting from the interaction between what is reflective (glass, flat metal, metal fabric) and what is reflected (sunlight, context, viewer), allows the scale of the architecture to be transformed by its material qualities, effectively neutralizing the inherent monumentality of the program and the form. [Fig. 12]

\section{Scaleless-ness}

Scaleless-ness can only occur when the project and its conceptual intentions can be experienced from a range of viewpoints; this scalar transformation is a result of the material qualities as experienced along the movement sequence into and through the building. In the Velodrome, primary pedestrian arrival moves through the dense urban blocks to the south or the solitary tower structures to the north and arrives at a stair rising one and a half meters from the street level to the park level; the park is invisible to all on the street. [Fig. 13] The park

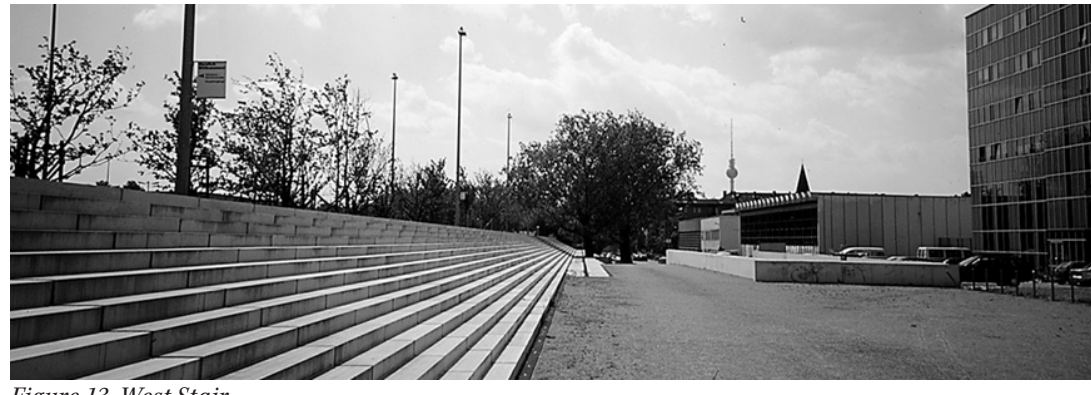

Figure 13. West Stair.

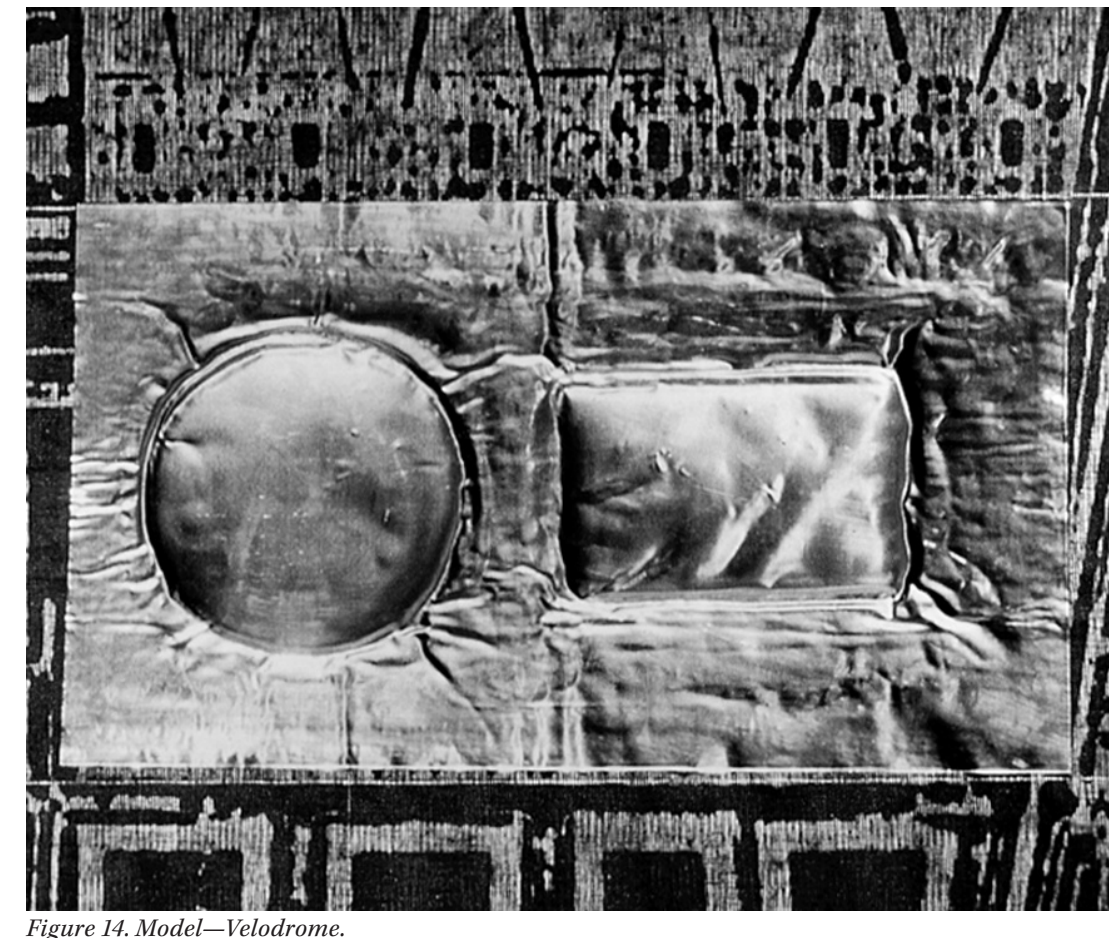

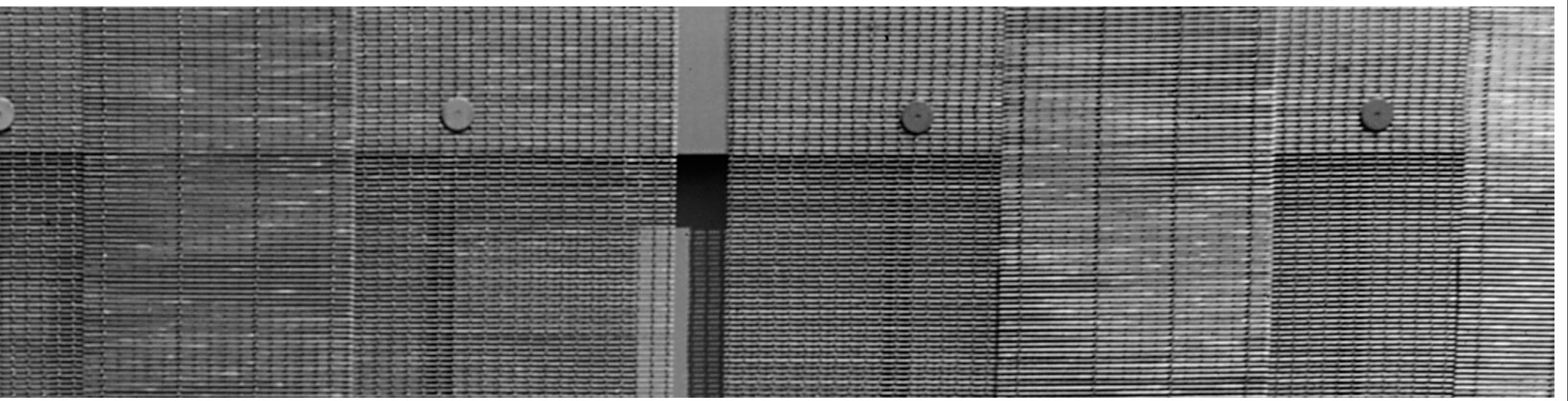




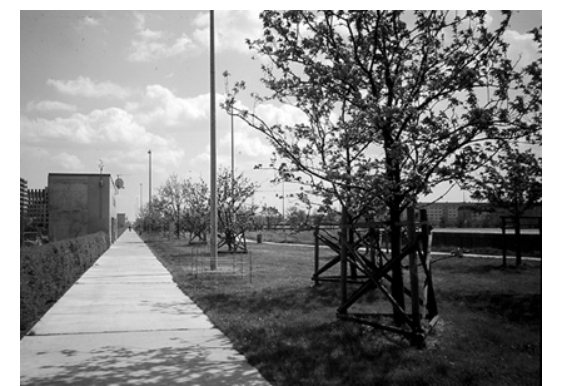

Figure 15. Park Looking West.

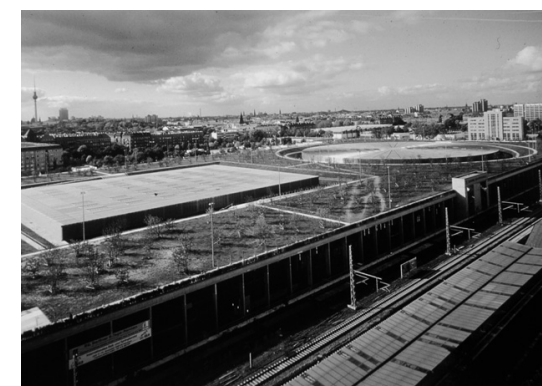

Figure 16.

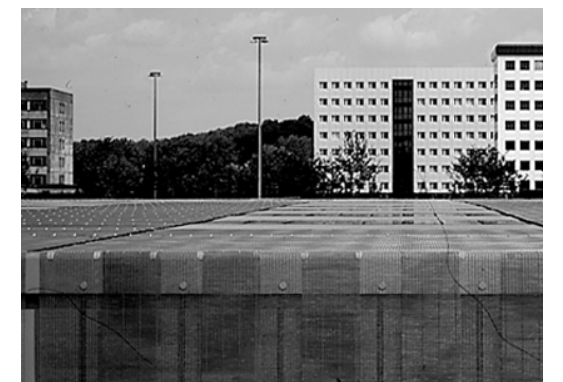

Figure 17. Roof-Velodrome.

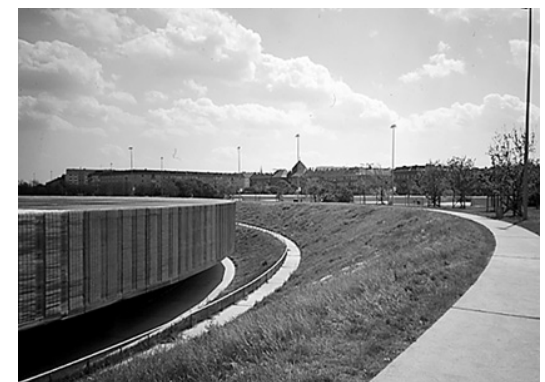

Figure 18. itself is vast (approximately $200 \mathrm{x}$ 500 meters); [Fig. 15] the only visual references are either the adjacent buildings in the background or the trees in the foreground. [Figs. 16, 24] Both lack formal order, causing the eye to meet the roof edges of the two large interior spaces..$^{15}$ These roofs are set exactly one meter above park level, causing their horizontal surfaces to be seen as shimmering metal carpets in a flattened perspective that increases their horizontality. [Fig. 25] This experience is further distorted by the sunlight moving over the metal fabric, which gives the surface an unpredictable rhythm that breaks the roofs' exaggerated scale down into a variety of more accessible ones. [Fig. 17] Smithson describes this same effect, where scaleless-ness can be understood as being about all scales: "the scale of the Spiral Jetty tends to fluctuate depending on where the viewer happens to be. Size determines an object, but scale determines art."16

From the park level, it is impossible to perceive both roofs simultaneously or to clearly register the building's form; neither the physical nor conceptual centers of the arenas can be easily perceived or reached. Both are surrounded by embankments too steep to walk down directly, and the only available paths spiral down and around them. Along these paths, the reference points of the trees and the surrounding buildings are lost; awareness is only the level of the entry. Here, standing between the grassy embankment and its reflection in the glass surface of the entries, the sky disappears. The reflective qualities of the surface create a direct connection between the new work and the context by visually coopting site, presenting a fractured view of both the landscape and the building through the slight modulation of the material's surface. ${ }^{17}$ These effects create an oscillation between the natural and a reflection of the natural, with no visible vanishing point except in the edge of the cantilevered metal skin overhead. [Figs. 18-22] The surface of the glass becomes a reference (map) to both a larger conceptual construct and an identifiable entity, generating the perceptual vibrations Smithson describes: "Light is separable from color and form...Color is the diminution of light. The cracked transparency of the glass heaps diffuse the daylight of the actual solar source-nothing is fused or connected. The map is a series of 'upheavals' and 'collapses'-a strata of unstable fragments is arrested by the friction of stability." 18

When entering the arenas, the viewer engages the structure of the immense roofs; entry is compressed and induces movement from the perimeter spatial layer to the centralized spaces containing viewers and events. [Fig. 28] These internal spaces have an inexact fit with the simple form implied by the structure and shape of the exterior roofs; [Fig. 23] rather than affording comprehension, the spatial vastness of the two halls throws the visitor from indeterminacy of perspective to incomprehensibility of scale: the void of the site is not only maintained through the exterior park sequence but through the emptiness of the internal program as well. Here the scaleless-ness is activated by the sunlight moving through the skylights over the layered rectilinear geometry of the Pool and complex curvatures of the Velodrome; [Fig. 26] this experience is heightened by the various human interactions that result from the event sequences within the arenas. From within the building, the only external reference is through the glass entry level that creates a thin new horizon line for a deep perspective, inverting the condition experienced initially on the surface of the park. [Fig. 27] This experience is heightened by the contrasting scales of every internal element; each particular structure (pool, diving platform, skybox) or surface (bicycle track, seating, lighting system) is clearly delineated with contrasting colors and materials. [Figs. 27, 29]

\section{Democratic Dialectics}

The Velodrome's articulation of timeless-ness and scaleless-ness through experience opens up the wealth of potential experience within the park to the entire city. This condition is inherently limitless because the elements within the system are able to change hierarchies and properties; they are allowed to de-differentiate.
The site intervention, the reclaimed site, must take existing elements and conditions and rework and reorder them to articulate this state. For the viewer the ability to physically exist between the architecture and the landscape allows us to simultaneously perceive the two and their interaction, and in this condition we must reconsider the place of all of these things - the building, the landscape, the sun, oneself-relative to one another.

What this potentially also proposes is that, through this interaction and understanding, we may arrive at a far different attitude toward our environment. The dynamic dialectic becomes what Smithson called a democratic dialectic, one where "a park can no longer be seen as 'a thing-in-itself', but rather as a process of ongoing relationships existing in a physical region-the park becomes a 'thingfor-us'...dialectics of this type are a way of seeing things in a manifold of relations, not as isolated objects. Nature for the dialectician is indifferent to any formal ideal." ${ }^{19}$ Perrault's work shares Smithson's understanding that no one system or factor can be consistently dominant in a project; by choosing instead to have a larger consciousness, an intentional re-conceptualization of the fields occurs, ultimately finding architecture, landscape and art interrelated. Transformation and simultaneity of all fields and relationships occur, in a continuous condition without hierarchy. 


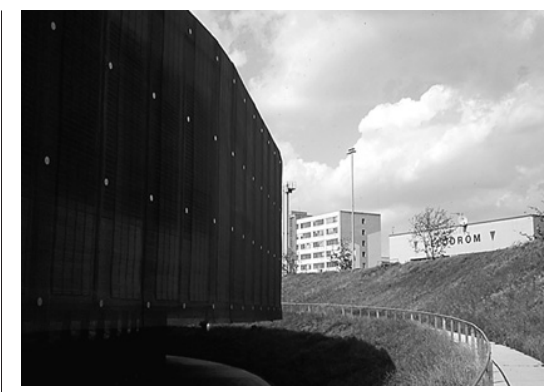

Figure 19.

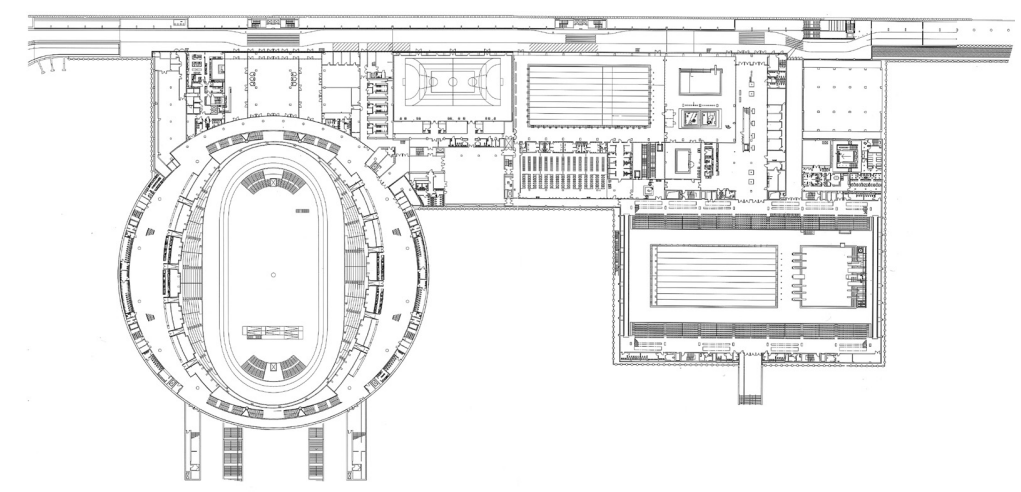

Figure 23. Plan-Below Park Level.

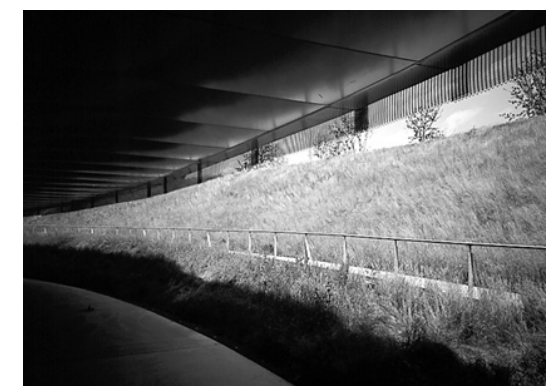

Figure 20.

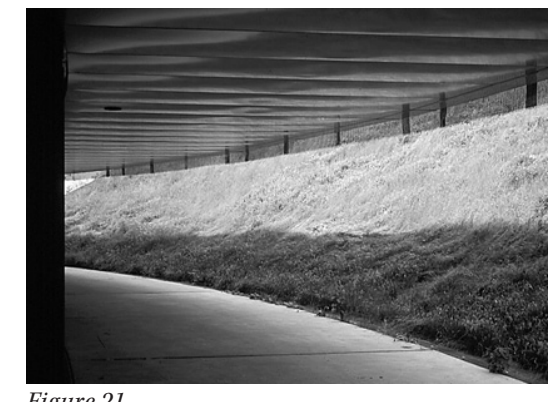

Figure 21.

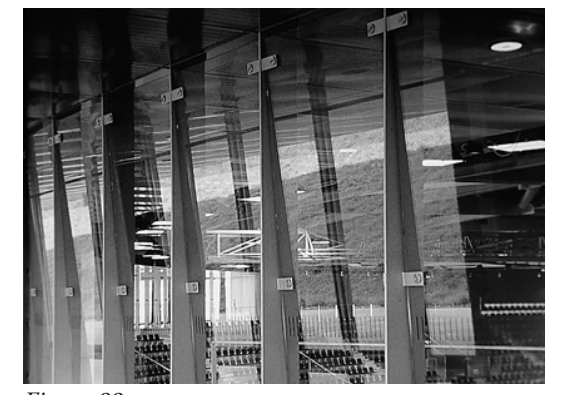

Figure 22.

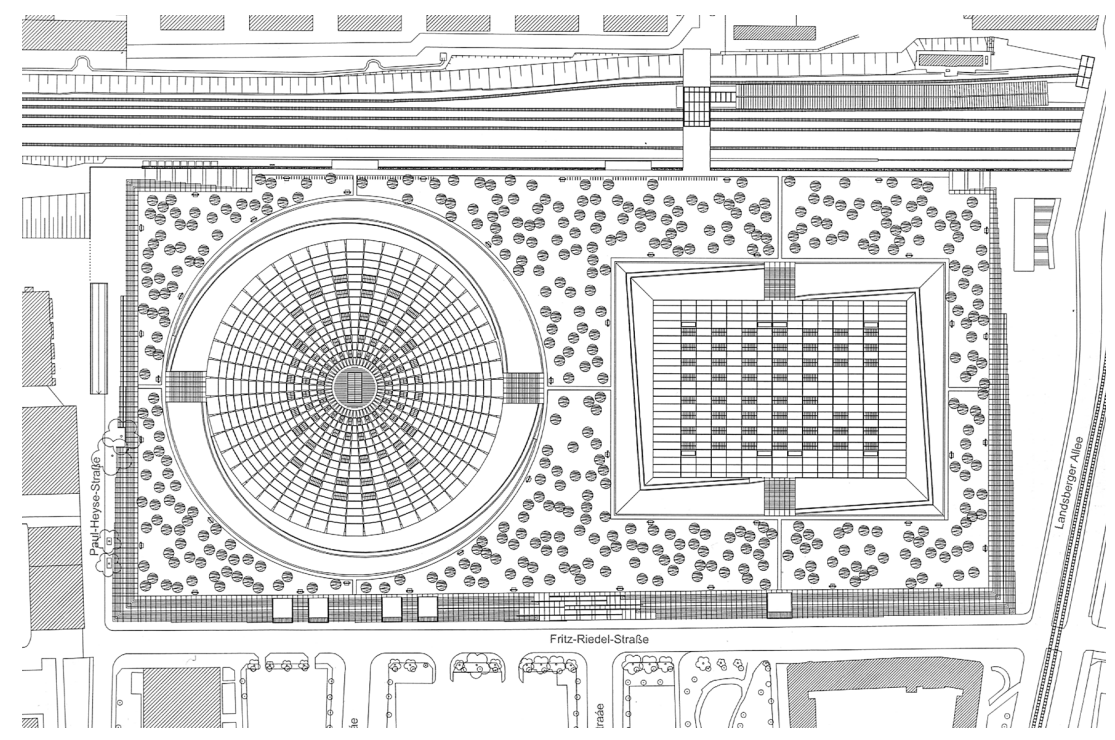

Figure 24. Site Plan.

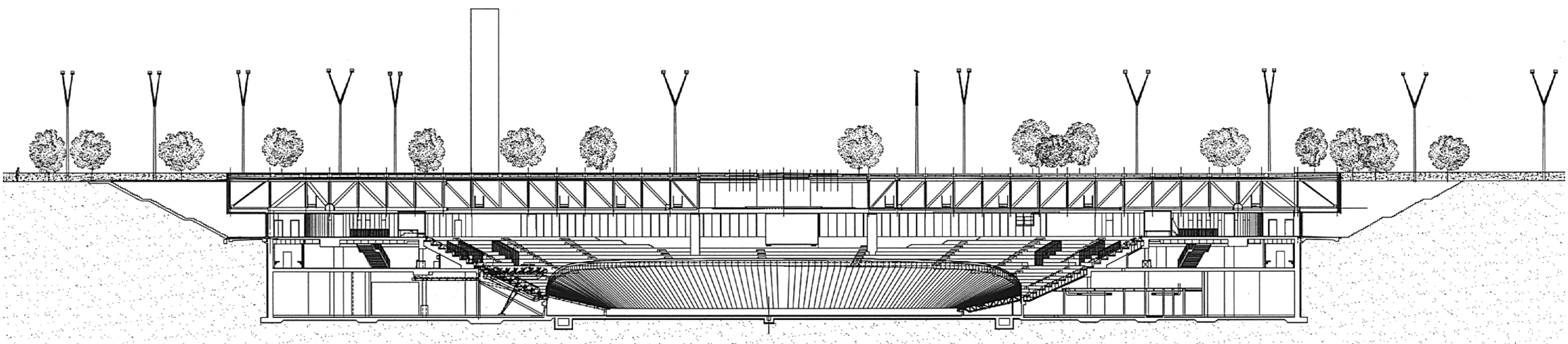



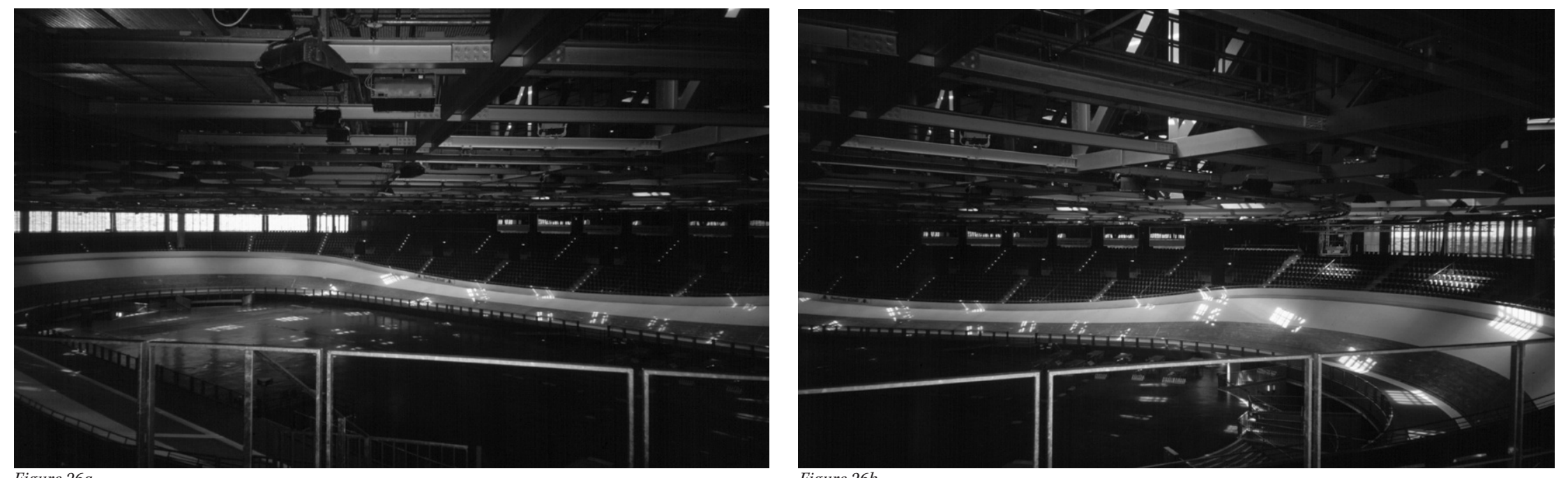

Figure 26a.

Figure 26b.
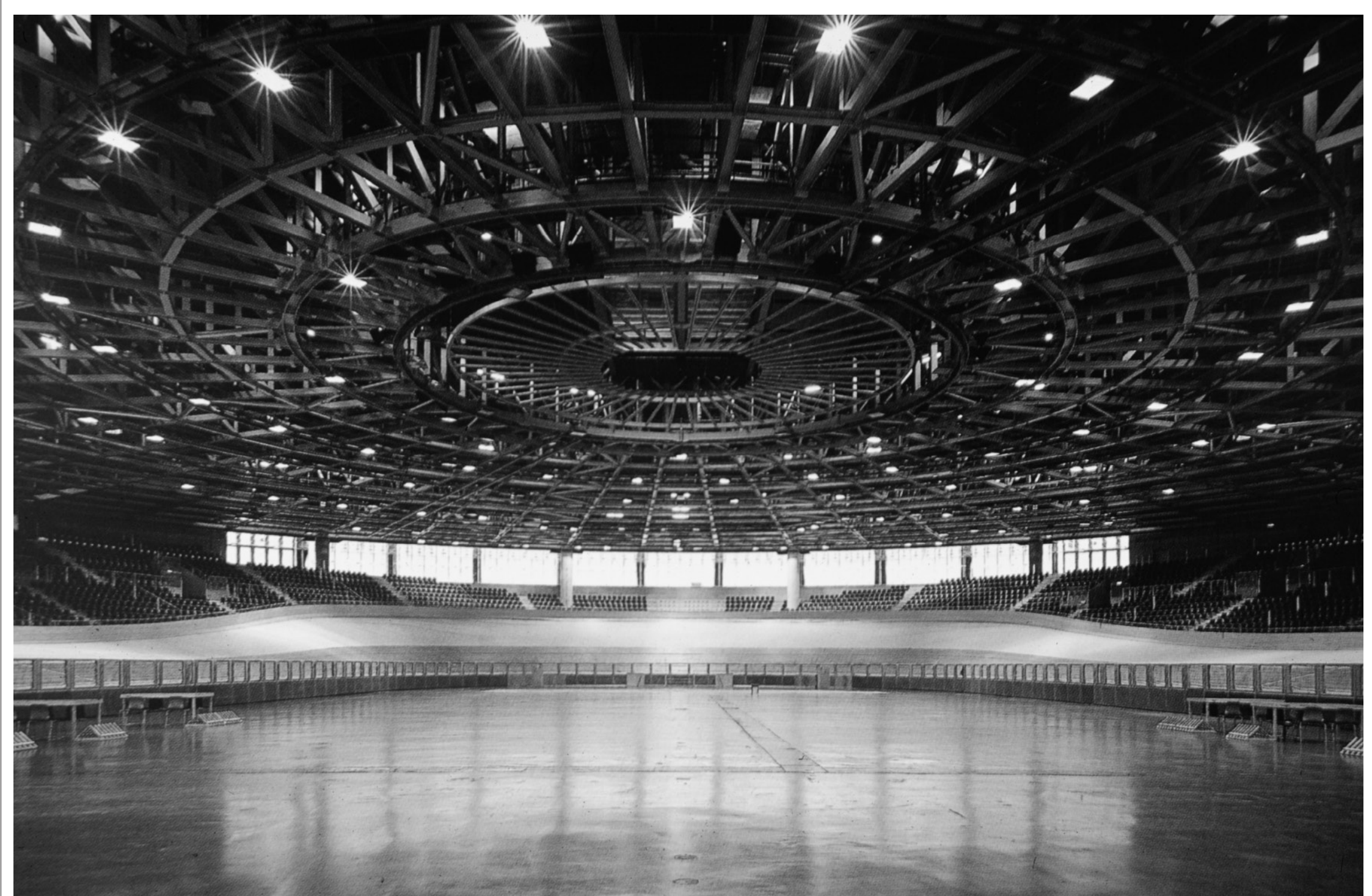


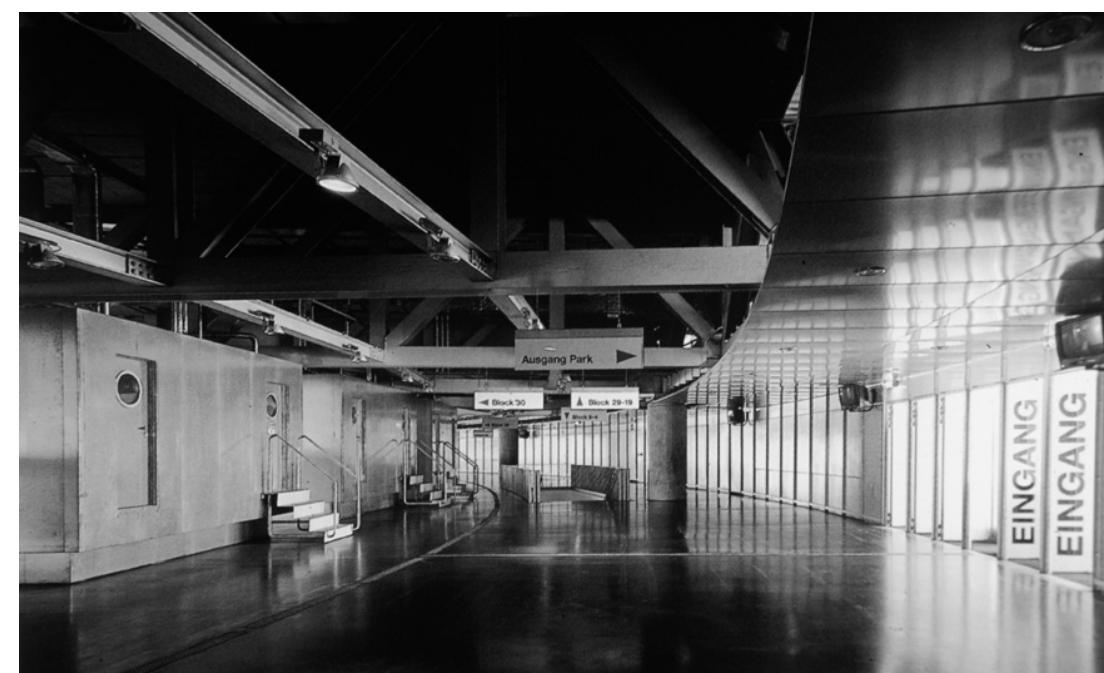

Figure 28. Entry-Velodrome.
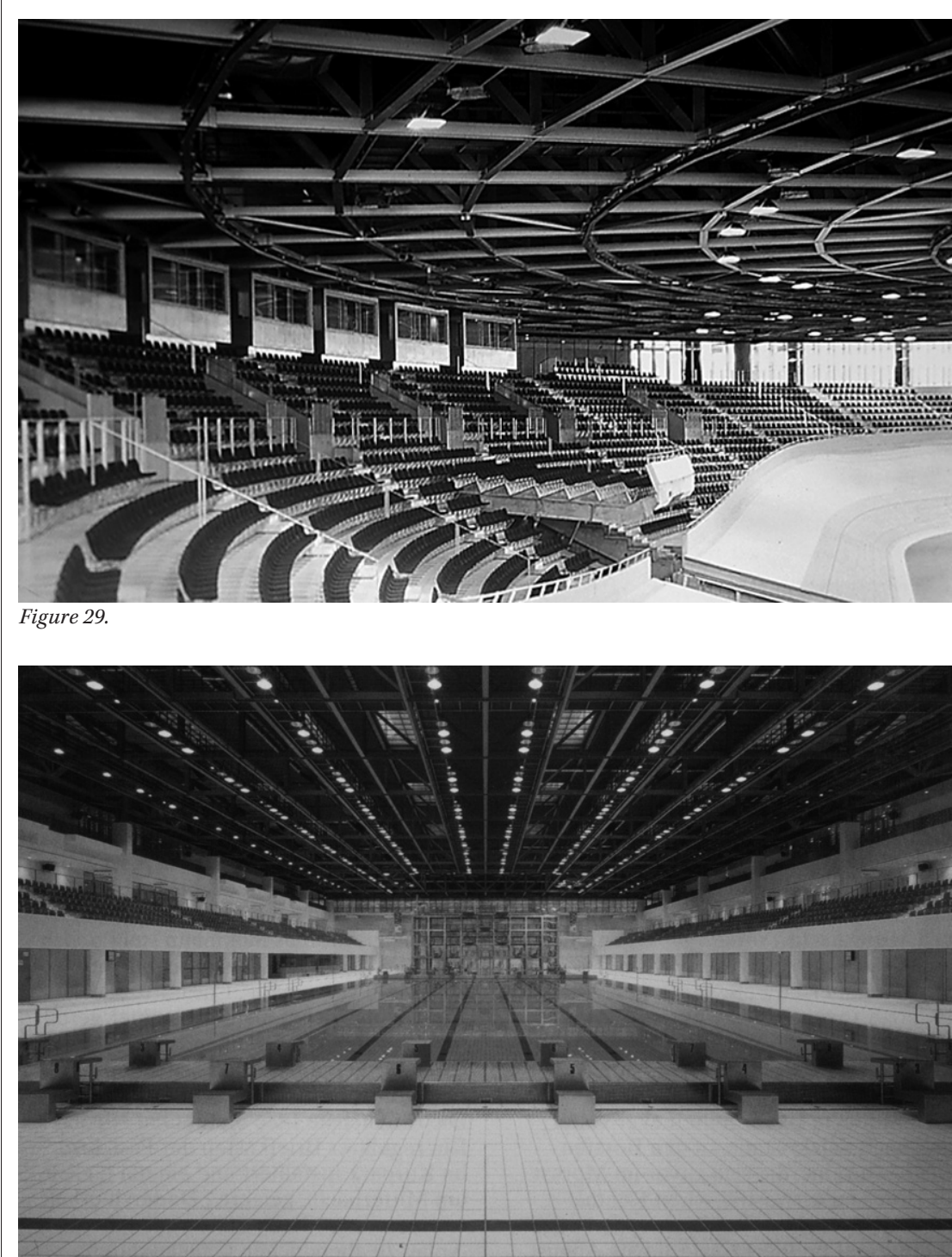

Figure 30 .

\section{Notes}

1. See Robert Smithson, "Incidents of Mirror-travel in the Yucatan," Artforum, no.9 (1969). Smithson's discussion of objects as sham-space recalls (and simultaneously rejects) the cerebral content of figure-ground relationships that drove post-modern architectural production. Without perceptual depth, object, or space-as-object, are devoid of content.

2. Odile Fillion, "Vision of Architecture of Dominique Perrault," Architecture+Urbanism 313, no.10 (1996): 42. Here Perrault is specifically discussing his development of the Velodrome.

3. Robert Smithson, "A Sedimentation of the Mind: Earth Projects," Artforum, (1968). Smithson concludes his article with a warning that any artist who does not understand (or at least attempt to understand) their relationship to time will ultimately undermine their entire artistic production. 4. Robert Smithson, "The Spiral Jetty" in: The Writings of Robert Smithson, (New York: NYU Press, 1979). While expanding on his ideas of time in the Artforum article, his commentary also indicates his desire to find, within any material, the ability to create perceptual vibrations that are at the limits of our experience.

5. See "Discussion with Heizer, Oppenheim, Smithson," Avalanche, (1972).

6. Kim Levin, "Reflections on Robert Smithson's 'Spiral Jetty'," Arts Magazine 52, no.9 (1978): 138 7. See Perrault's project for the UNIMETAL Site (Normandie, France 1997) and Smithson's aerial art proposals for the Dallas-Fort Worth Airport (1967).

8. Jacques Lucan, "Architecture: Bare Fact and Neutral Writing," Dominique Perrault, (Zürich: Artemis Verlag, 1994): 6. Particularly relevant to this technique are the drawings for The Two Banks of the Garonne in Bourdeaux (1992) and the Wilhelm Galerie in Potsdam (1993).

9. This relates to the site / non-site theory as discussed in "Discussion with Heizer, Oppenheim, Smithson" (1972).

10. Patrick Werkner, Land Art USA, (München: Prestel Verlag,1992): 87. See also Robert Smithson, "A Sedimentation of the Mind: Earth Projects" (1968).

11. See Frederic Migayrou, "Computational Architecture" in: Dominique Perrault: El Croquis 104 (2001). In the interview, Perrault discusses and rejects postmodern ideas of reconstruction and urbanization, a particularly telling response given the city planning attitudes promoted in Berlin at the time of his project.

12. The original competition proposal involved urban planning of the immediate vicinity; Perrault proposed a series of office towers along one edge of the park to afford this aerial viewpoint to all that worked there.

13. Perrault investigated these issues at a smaller scale in the Koloniehavehus installation in Copenhagen (1996).

14. See Martin Kieren, "Dominique Perrault: Classical Architect and Magician," Dominique Perrault, (Zürich: Artemis Verlag, 1994) for an extensive discussion on Perrault's development of the materials he uses.

15. The original competition project proposed the use of native German apple trees, which required planting in a grid and careful care; in the realization, they were replaced with French apple trees which grew wilder and required less care and precision planting.

16. David Bellman, "Robert Smithson and Frederick Law Olmsted: Earthworks in the Future Anterior," Arts Magazine 52, no.9 (1978):127. This could also begin to define timeless-ness as being about all times.

17. Dominique Perrault and Andre Morin, Aplix, (Baden: Lars Müller Publishers, 1999). The Aplix Factory in Nantes (1997-99), where the highly polished metal skin allows integration with the agricultural context, also recalls Smithson's Mirror Displacements (1968), where a series of square mirrors set in different landscapes capture the most primitive aspects of the site-view and light-and place it in a removed (framed) condition. Both projects and the issues they articulate recall the work of Superstudio, in particular the Continuous Monuments series (1969) and The Twelve Ideal Cities (1971). Although purely theoretical, their work was particularly interested in investigating the relationship between the sylvan and the industrial. For Perrault, the reflective materiality of Aplix directly references 2000-Ton City (1971).

18. This quotation, taken from the notes for "Incidents of Mirror-travel in the Yucatan" (1969), refers directly to The Map of Glass (1969).

19. See Robert Smithson, "Frederick Law Olmsted and the Dialectical Landscape," Artforum, no.2 (1973). This article details Smithson's description of the democratic dialectic between the sylvan and the industrial. 